\title{
The Role of Culture in Interface Acceptance
}

\author{
Vanessa Evers ${ }^{1}$ and Donald Day ${ }^{2}$ \\ ${ }^{1}$ Faculty of Mathematics, Computer Science, Physics and Astronomy, \\ The University of Amsterdam, \\ 1000 GG Amsterdam, the Netherlands \\ Vanessa@infosys7.infosys.unsw.edu.au \\ ${ }^{2}$ School of Information Systems, The University of New South Wales, \\ Sydney NSW 2052 Australia \\ Donald_Day.chi@xerox.com
}

\begin{abstract}
In order for global software to be marketed successfully, the design of interfaces should accommodate users' cultural differences. This study examines users' culturally specific design preferences, and evaluates the attitudinal and behavioural consequences of satisfying or not satisfying such preferences. Participants consist of 206 international students, plus a control group of 38 Australian students. Results indicate that design preferences do affect interface acceptance, but that the path of influence leading from preference to attitude and behaviour varies from culture to culture. In particular, unexpected differences are noted between Chinese and Indonesian subjects. Conclusions emphasise the need for confirmatory research, both in terms of interface acceptance and in the design of information systems.
\end{abstract}

KEY WORDS globalisation, culture, interfaces, attitudes, user behaviour

\section{INTRODUCTION}

This paper discusses cultural factors in user acceptance of human-computer interfaces. It is grounded in beliefs that culture is a discernible variable in interface acceptance, and that interfaces designed for globally marketed software should accommodate users' cultural differences.

Most studies in this area approach acceptance issues from an ease of use and usefulness point of view (Davis, 1993; Hubona, 1996; Igbaria, 1994; Thovtrup, 1991). Some international interface design literature discusses the "internationalisation - localisation strat- egy" from an implementation point of view (Taylor, 1992; Luong et al, 1995; Uren et al., 1995). Other work, however, uses a more conceptual approach (Russo, 1993; Teasley et al, 1994; del Galdo, 1990; del Galdo et al, 1996). Russo and Boor (1993) deal with

A range of cross-cultural elements that need to be considered by the interface designer: Text, Number, Date and Time Formats, Images, Symbols, Colours, Flow and Functionality.

Russo and Boor also discuss social norms and intuitive behaviour that influence the use of such elements. Fer-

Human-Computer Interaction: INTERACT'97 S. Howard, J. Hammond \& G. Lindgaard (editors)

Published by Chapman \& Hall OIFIP 1997 
nandes (1995) gives developers specific interface design advice, based on his experience developing international software at Claris Corporation, and modelled on various countries' non-IT consumer products, advertising, traffic signs and architecture.

Studies comparing cultures in terms of information technology find significant differences in attitudes toward computers (Igbaria and Zviran, 1996; Choong \& Salvendy, 1997; Omar, 1992). The cultural environment people live in is assumed to have a strong effect on how they conceptualise reality (Allwood, 1990).

To a certain extent, the interface is a marketing tool, just as vital to sales as is packaging for soft drinks. de Kerckhove (1991) describes design as a technology's public relations, sharpening its image in the marketplace. It is the "visible, audible or textual outer shape of cultural artefacts".

In the pilot study reported here, we address only globally marketed software packages. We ignore Usenet, Internet and other cyberspace facilities. We examine the extent to which culture influences user preferences in interface design. We also review whether these influences are consistent with established theories of cultural orientation (Hall, 1959; Hofstede, 1991; Trompenaars, 1993).

\section{RESEARCH MODEL}

This research uses the modified technology acceptance model (Figure 1), first proposed in Day (1996a). That model is based on Davis (1993), whose approach has been changed to incorporate cultural aspects.

\subsection{Culturally specific design preferences}

This first construct represents what users want the system to look like and what functionality should be included. For example, Sukaviriya et al (1990) tells us that in some Asian scripts there is no upper or lowercase letter writing. Under these circumstances, a function to change case would be completely useless. It would be irrelevant to user expectations.

\subsection{Beliefs about system usefulness}

This construct represents "the degree to which an individual believes that using a particular system would enhance his or her job performance" (Davis, 1993).

\subsection{Perception about system ease of use}

This construct represents "the degree to which an individual believes that using a particular system would be free of mental or physical effort" (Davis, 1989).

Ease of use may be defined experientially as well as culturally. For example, for people in the Arabic world a right-to-left flow of information seems natural. However, many Arabic users are so familiar with American software that they might find a different, culturally adapted design hard to adjust to -- even if it were more intuitive.

\subsection{Attitude of satisfaction in using}

This construct represents the degree to which a user's perceived personal needs and the need to perform specific tasks satisfactorily are met by a system (Goodhue and Straub, 1991).

\section{RESEARCH PROPOSITIONS}

Five propositions were developed directly from the research model (Figure 1).

1. Users' culturally specific design preferences influence their beliefs about system usefulness while using globally marketed software.

2. Users' culturally specific design preferences influence their perceptions about system ease of use while using globally marketed software.

3. Users' beliefs about system usefulness influence their attitudes of satisfaction while using globally marketed software.

4. Users' perceptions about ease of use influences their attitudes of satisfaction while using globally marketed software.

5. Users' attitudes of satisfaction in using globally marketed software influence their anticipated system use behaviour with such products.

\section{METHOD}

\subsection{Sample}

The international subjects were 206 students from the Foundation Studies Program of The University of New South Wales (UNSW), Sydney, Australia. Subjects 


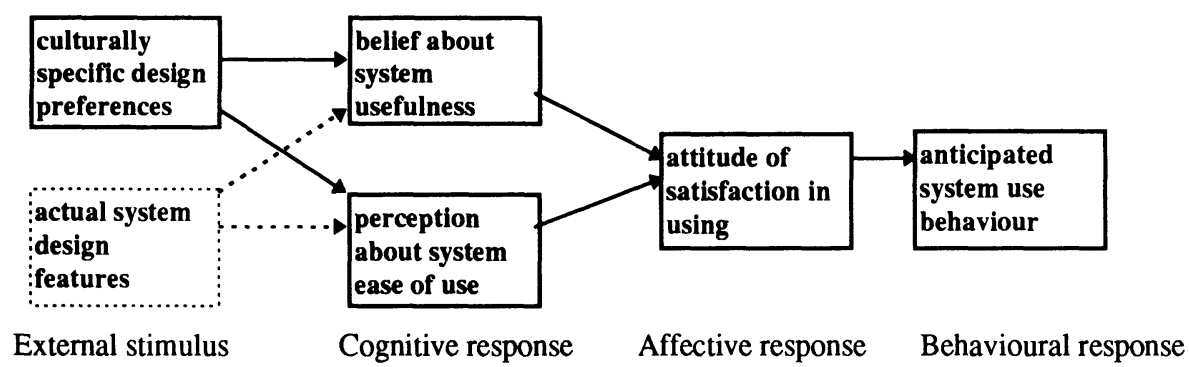

Figure 1. Modified Technology Acceptance Model (after Davis, 1993)

were chosen because of participation in an orientation program, which we felt would encourage their co-operation.

The sample consisted of three main groups: Indonesians (44 males, 31 females), Chinese and Hong Kongese (27 males, 39 females), and "Others" (33 males, 27 females). This latter group was largely from other Asian countries like Taiwan, Singapore and Japan. Thus, subjects were excluded from data analysis because their numbers would not support statistical significance. The majority of subjects were between 18 and 21 years old, had some computer experience, and had a fair knowledge of English. Chinese and Indonesian subjects were assigned to their groups on the basis of language, cultural identification, amount of exposure to other cultures, and length of time family had lived in a specific area.

An Australian control group consisted of 38 undergraduate students from UNSW, selected for dominant culture homogeneity and relative lack of multicultural influence. Twenty-seven of these students were male, 11 female. Most were between 18 and 21 years old, and had some computer experience. This control group was included to ensure that observed effects would in fact be due to cultural differences, rather than to extraneous non-cultural factors. (If an effect were similar in both the main sample and in the control group, cultural differences could not be presumed to be the cause.)

\subsection{Materials and procedure}

Data were collected by means of an eight-page questionnaire. The questionnaire was reviewed in advance by both the UNSW Institute of Languages and the
UNSW Institute of English Language, to ensure that questions were culturally neutral (Day \& Evers, 1997). This instrument consisted of 39 anchored Likert-scale items, 22 open-ended questions, 15 forced-choice selections, and one battery of three scenario-based options.

The survey was administered during a pre-session orientation sponsored by the UNSW Foundation Studies Program. Subjects were allowed 40 minutes to complete the questionnaire. Control group data were collected in two tutorials at the UNSW School of Information Systems.

\subsection{Measures}

Key research model constructs were operationalised as follows.

Culturally specific design preferences. Eighteen interface design features were presented to subjects. Response options were anchored on a 6-point Likert scale.

Belief about system usefulness. This construct was measured by asking to what extent computers would be better in performing certain actions. This was operationalised as preferences.

Perception about system ease of use. The perceived ease of use of a culturally adapted interface, and users' input device.

Attitude of satisfaction in using. Subjects were asked how satisfied they would be in using culturally sensitive software.

Anticipated system use behaviour. Subjects were asked whether it would take more or less time to learn a system designed for their culture, compared to one with 
a universal interface.

In addition, potential confounds such as age, gender, experience, economical situation, opportunity in education, direction used while reading scripts, contact with technology, and contact with other cultures were assessed to evaluate potential extraneous influences in the findings.

Since the study was designed to assess the cultural bases of interface acceptance, several culturally specific variables were examined to judge their impact on key constructs in the research model. Included were variables addressing

- uncertainty avoidance (whether uncertainty is perceived as threatening; Hofstede, 1991),

- need for significant others,

- parallel versus sequential actions (to do 'more things at once' or 'one thing at a time'),

- diffusion versus specificity (whether business and personal relationships are separated clearly; Trompenaars, 1993),

- particularism versus universalism (whether behaviour is rule-based versus relationship-based; Trompenaars, 1993),

- collectivism versus individualism (whether people like to work and make decisions in groups versus alone; Hofstede, 1991; Trompenaars, 1993),

- high context versus low context (whether meaning resides in context, or that information instead should be stated explicitly), and

- transference (the extent to which a person blames others or one's self).

A description of these variables can be found in (Hoft, 1990).

\subsection{Statistical analysis}

Following data entry using SPSS-PC, univariate statistics were generated for all questions. Response items were combined using reliability analysis techniques, to create scales for design preferences $(\alpha=.8)$, to assess system usefulness $(\alpha=.77)$, and for creation of a culture of origin profile $(\alpha=.62)$. Reliability levels for all three scales are high enough to be deemed sufficient (DeVellis, 1991). Data were corrected for a 12.3 percent item response bias, then re-categorised into 5-point response scales.
Next, Pearson correlations were run for interconstruct effects as predicted by the research model, and cross-tabulations were generated to add texture to the interpretation of significant correlations.

\section{RESULTS}

\subsection{Descriptive statistics}

In this section, statistics from the largely Asian main sample are followed (in parentheses) by corresponding results from the Australian control group.

In terms of user expectations, $72.9 \%$ (28.9\%) liked lots of different colours, $68.3 \%(31.6 \%)$ liked soft colours, $54.2 \%(63.2 \%)$ liked pull down menu's, $54.3 \%$ (31.4\%) liked fixed menu's, $43.1 \%$ (8.3\%) liked text based interfaces, and $63.8 \%$ (78.4\%) liked GUI interfaces.

In regard to input and output devices, we found that $88.5 \%(72.2 \%)$ liked using a mouse, $66.2 \%(21.1 \%)$ liked joysticks, and $73.1 \%(47.1 \%)$ liked touch screens. In all, $86.5 \%(64.9 \%)$ strongly liked sounds.

In examining user satisfaction, we found that $67.9 \%$ $(86.8 \%)$ would be satisfied using technology adapted to their culture. Only $34 \%$ (65.8\%) thought it would take less time to learn a culturally adapted interface. And $52.7 \%(34.2 \%)$ preferred to instruct a machine with detailed commands rather than providing only general direction.

In examining cultural variables, we found that $68.7 \%(39.5 \%)$ scored high on uncertainty avoidance. About $75.6 \%(57.9 \%)$ were found to be diffuse, and $40.8 \%(18.4 \%)$ tended towards universalism. About $40.8 \%$ percent $(36.8 \%)$ were collectivist, and $59.7 \%$ (100\%) had a high context orientation.

In analysing these univariate results, we drafted the following interface preferences profile for Asian users of globally marketed software. Its validity will need to be verified in future research involving subjects responding from within their home cultures.

Asians prefer soft colours, fixed (versus pull-down) menus, and explicit, text-based (not symbolic) interfaces. They like the mouse as an input device best, with the touch screen second. Sound is somewhat important, as well.

Asians place relatively low value on the cultural adaptiveness of software, possibly because they believe 
Table 1

INTERFACE DESIGN PREFERENCES, CHINESE VS. INDONESIANS

\begin{tabular}{|l|l|l|l|c|c|}
\hline \multicolumn{2}{|l}{ Chinese $(\mathrm{n}=66)$} & & \multicolumn{3}{c|}{ Indonesian $(\mathrm{n}=75)$} \\
\hline Mean & $\mathrm{SD}$ & Interface Design Features & Mean & SD & $\mathrm{F} 1, \mathrm{p}<.05$ \\
\hline 3.09 & 1.2 & Strong bright colours & 3.55 & 1.2 & $\mathrm{NS}$ \\
2.56 & 1.0 & Soft colours & 2.09 & 0.8 & 5.2 \\
2.00 & .9 & A lot of different colours & 2.37 & 1.1 & 5.3 \\
4.45 & 1.0 & Black and white displays & 3.95 & 1.3 & 15.9 \\
3.06 & 1.0 & Text based interfaces & 2.70 & 0.9 & NS \\
2.34 & .9 & GUI & 2.36 & 1.1 & NS \\
2.32 & .8 & Windows & 2.37 & 0.8 & NS \\
2.41 & 1.0 & Pop-up menus & 2.15 & 0.8 & 5.7 \\
2.60 & 0.8 & Pull-down menus & 2.59 & 1.0 & NS \\
2.69 & 0.8 & Fixed menus & 2.33 & 0.9 & NS \\
1.74 & 0.8 & Mouse & 1.64 & 0.8 & NS \\
2.35 & 1.2 & Joystick & 2.22 & 1.1 & NS \\
2.13 & 1.1 & Touch screen & 1.88 & 0.8 & 6.9 \\
2.22 & 1.0 & Data glove & 1.81 & 0.8 & 4.5 \\
1.76 & 0.8 & Sounds & 1.52 & 0.7 & 3.6 \\
1.62 & 0.8 & Multimedia & 1.41 & 0.5 & 12.8 \\
\hline
\end{tabular}

Notes (1) NS = non-significant; (2) In terms of means, the smaller the number the more strongly the feature is preferred.

it would take longer to learn culturally adaptive interfaces. They also prefer to instruct computers using detailed commands.

In terms of intercultural anthropology, Asians tend to mix private and business matters, see uncertainty as threatening, consider relationships and trust important, and prefer to work in teams.

That Asians prefer to instruct computers using detailed commands, find uncertainty as threatening, and prefer text-based rather than symbolic interfaces is not what one would expect from the orthodox intercultural literature.

One of the key findings of this study was that there are not only interface-relevant cultural differences between Asians and Australians (as expected), but that significant differences also exist within Asian groups -specifically, between Indonesians and Chinese.

Table 1 shows the mean interface design feature preferences expressed by these two Asian subsamples. These data suggest that Indonesians like soft colours, black and white displays and pop-up menus more than do Chinese. Also, Indonesians seem to like new technology and alternative input and output (e.g., sounds, touch screens, data gloves and multimedia) more than do Chinese. On the other hand, the use of many different colours seems more appropriate for Chinese.

\subsection{Associative statistics}

Figure 2 summarises significant correlation results. Although correlations were not very substantial, we found enough significant relationships to support the research model.

Culturally specific design preferences relate significantly to system usefulness in all three groups (Proposition 1). The relation seems to be the strongest for the Chinese.

Design preferences influence ease of use (Proposition 2) for the total sample and for the Indonesian subgroup. There are significant relations between system usefulness and attitude of satisfaction (Proposition 3), between ease of use and attitude of satisfaction (Proposition 4), and between attitude of satisfaction and anticipated system use behaviour (Proposition 5).

It is interesting to note that the acceptance process seems to flow differently for the two subgroups. For the 


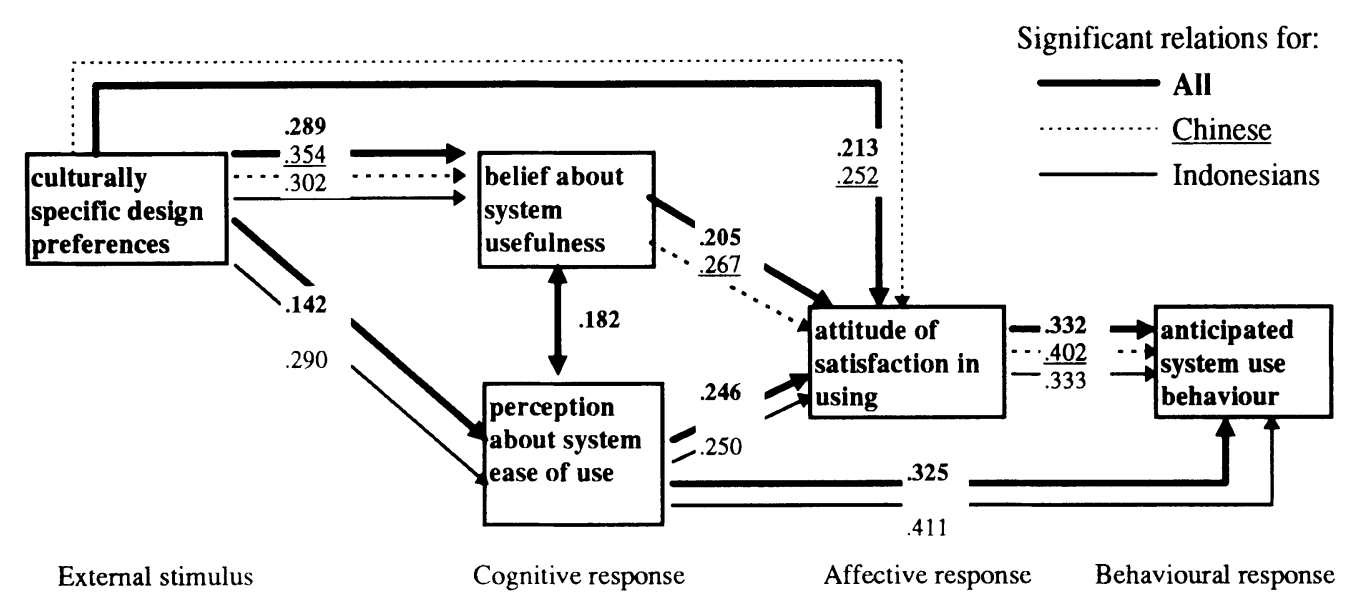

Figure 2. Significant Correlation Results Note Every significant interconstruct relationship is represented by an arrow. Correlations are in bold for the entire sample, underlined for the Chi-
nese, and in regular type for the Indonesians.

Chinese, acceptance is routed through preferences, usefulness and attitude of satisfaction. However, for the Indonesians it seems to move along the ease of use side of the model. Also, ease of use seems to influence behaviour more strongly than does attitude of satisfaction.

This implies that for the Indonesians, user preferences do influence both their beliefs about system usefulness and their perceptions about ease of use. However, it seems that the Indonesian user is only satisfied by the usability of the system. System use behaviour also is affected by perceived ease of use.

In contrast, results suggest that Chinese attitudes of satisfaction are attributable to user preferences and beliefs about usefulness. System use behaviour is attributable to attitudes of satisfaction, as expected.

We found that cultural variables relate significantly to interface design preferences for the main sample, as well as for the Chinese and Indonesian subgroups.

System ease of use and system usefulness affect each other only in the main sample, with a very weak correlation. Because of this, we can assume there is no interconstruct relationship between ease of use and usefulness.

The most interesting observation in the Australian control group is that neither ease of use nor usefulness seem to drive attitude of satisfaction (propositions 3 and 4). Attitude of satisfaction is influenced by culturally specific preferences in design and by cultural variables.

\section{DISCUSSION}

\subsection{Conclusions}

This research sought to extend previous research by examining the Davis (1993) model in a cultural context. Findings demonstrate the existence of cultural differences in terms of interface acceptance in globally marketed software. Not only do groups have different preferences in design features, but there also are differences in the acceptance process.

It seems that Chinese find usefulness a more discernible variable, while ease of use (which also directly influences system use behaviour) is more important for Indonesians. This suggests that Chinese will try to work with a useful interface, even when it is hard to use. Indonesians, however, will tend to give up more easy when an interface is hard to understand. This finding could be related to anthropological literature that describes Indonesians as higher in uncertainty 
avoidance than the Chinese (Hofstede, 1991). It could explain as well the importance of a usable interface for Indonesians.

Also interesting is the fact that Indonesians' beliefs about ease of use directly influence their anticipated system use behaviour. This implies that when they find a system easy to use, they expect to be happy in using the system. It seems that being genuinely satisfied with the system is less important than the knowledge that it will be easy to use.

It is hard to explain why preferences in interface design directly influence Chinese attitudes of satisfaction. This effect implies that when preferences for design features are met, users will be satisfied with the interface. There seems to be no need to find out whether the interface is easy to use. Maybe Chinese find that their demands for ease of use are met when the interface looks the way they want it to. Usefulness influences their attitudes of satisfaction as well. Therefore, we can assume that a system's external design features are not enough to satisfy the Chinese. Certain functionality levels must be met, as well.

Within the Australian control group, attitudes of satisfaction also were influenced directly by design preferences. This suggests that in this sense Australians are similar to Chinese. However, the Australians' lack of a need to fulfil ease of use and usefulness demands in order to feel satisfied is worth noting. It seems that Australians find an interface satisfactory when it meets their preferences in interface design even if the system is either hard to use or not useful to them. It could be that Australians separate interface satisfaction from system satisfaction; perhaps they can be dissatisfied with a system, while at the same time being satisfied with the interface they are using. This would suggest they put more emphasis on the way an interface looks than on the functionality it provides.

The finding that different groups form different paths through the research model (Table 2) supports the supposition that human-computer interface acceptance is indeed influenced by culture.

These subjects are not believed to be atypical in any substantial way versus their reference populations. Therefore, these findings are at least generisable to Asians of the age group from which these subjects were drawn.
Table 2.

CULTURALLY BASED ACCEPTANCE PATHS

Chinese

preferences $\Rightarrow$ usefulness $\Rightarrow$ satisfaction $\Rightarrow$ behaviour

Indonesians

preferences $\Rightarrow$ ease of use $\Rightarrow$ satisfaction $\Rightarrow$ behaviour

Australians

preferences $\Rightarrow$ satisfaction $\Rightarrow$ behaviour

\subsection{Future research}

The current study is the pilot for a larger, multi-year effort. The authors are aware of its several methodological shortcomings (Day, 1996b). In particular, the lack of strong correlations and the use of international students rather than workplace subjects are of concern.

Future research will include alternate data collection modes such as interviews, direct observation of user behaviour, and focus groups. Also, questionnaires will be administered to overseas subjects in their home cultures, to minimise potential cultural contamination problems.

\section{REFERENCES}

Allwood, C. \& Wang, Z-M. (1990). Conceptions of computers among students in China and Sweden. Computers in Human Behaviour 6, 185-199.

Choong, Y-Y \& Salvendy, G. (1997). Design of icons for use by Chinese in mainland China. In "Shared Values and Shared Interfaces", a special issue of Interacting with Computers (forthcoming).

Davis, F. (1989). Perceived usefulness, perceived ease of use, and user acceptance of information technology. MIS Quarterly 13, 319-340.

Davis, F. (1993). User acceptance of information technology: system characteristics, user perception and behavioural impacts. International Journal of Man Machine Studies 38, 475-487.

Day, D. (1996a). Cultural bases of interface acceptance: foundations. In People and Computers XI, 35-47. Proceedings of HCI'96 (August 20-23, 1996, Imperial College). London: Springer-Verlag.

Day, D. (1996b). Cultural bases of interface acceptance: 
methods. In Proceedings, 2nd AIS Americas Conference, 716-718. (August 15-18). Phoenix: Assn. for Information Systems.

Day, D. \& Evers, V. (1997). Instrument development for multicultural usability studies. Submitted to People and Computers XII (HCI' 97). Bristol, UK, 13-15 August

DeVellis, R. (1991). Scale Development: Theory and Applications. Newbury Park, Calif.: Sage.

Fernandes, T. (1995). Global Interface Design. London: Academic Press.

Del Galdo, E. (1990). Internationalisation and translation: some guidelines for the design of human computer interfaces. In J. Nielsen (Ed.), Designing User Interfaces for International Use, 1-10. New York: Elsevier.

del Galdo, E. \& Nielsen, J. (1996). International User Interfaces. New York: Wiley.

Goodhue, D. \& Straub, D. (1991). Security concerns of system users. Information \& Management 20(1), 13-27.

Hall, E. (1959). The Silent Language. New York: Doubleday.

Hofstede, G. (1991). Cultures and Organisations: Software of the Mind, 125. New York: McGraw-Hill.

Hoft, N. (1990). Developing a cultural model. In J. Nielsen \& E. del Galdo (Eds.), Designing User Interfaces for International Use, 41-73. New York: Elsevier.

Hubona, G. \& Blanton, J. (1996). Evaluating system design features. International Journal of Human Computer Studies 44, 93-118.

Igbaria, M., Schiffman, S. \& Wieckowski, T. (1994). The respective roles of perceived usefulness and perceived fun in the acceptance of microcomputer technology. Behaviour and Information technology $13,349-361$.
Igbaria, M. \& Zviran, M. (1996). Comparison of enduser computing characteristics in the US, Israel and Taiwan. Information and Management 30, 1-13.

de Kerckhove, D. (1991). Brainframes: Technology, Mind and Business. Utrecht, the Netherlands: Bosch \& Keuning BSO/ORIGIN.

Luong, T., Lok, J., Taylor, D. \& Driscoll, K. (1995). Internationalisation: Developing Software for Global Markets. New York: John Wiley \& Sons.

Omar, M. (1992). Attitudes of college students towards computers: a comparative study in the Middle East. Computers in Human Behaviour 8, 249-257.

Russo, P. \& Boor, S. (1993). How fluent is your interface? designing for international users. Human Factors in Computing Systems, 24-29. Proceedings of INTERCHI '93, Amsterdam. New York: ACM.

Sukaviriya, P. \& and Moran, L. (1990). User interfaces for Asia. In J. Nielsen (Ed.). Designing Interfaces for International Use, 189-218. New York, Elsevier.

Taylor, D. (1992). Global Software: Developing Applications for the International Market. New York: Springer-Verlag.

Teasley, B., Leventhal, L., Blumenthal, B., Instone, K. \& Stone, D. (1994). Cultural diversity in user interface design: are intuitions enough? SIGCHI Bulletin 26(1), 36-40.

Thovtrup, H. \& Nielsen, J. (1991). Assessing the usability of a user interface standard. $\mathrm{CHI}^{\prime} 91 \mathrm{Hu}$ man factors in Computing Systems, 335-341. Proceedings of CHI'91. New York: ACM.

Trompenaars, F. (1993). Riding the Waves of Culture: Understanding Cultural Diversity in Business, 6-10. London: Nicholas Brealey.

Uren, E., Howard, R. \& Perinotti, T. (1995). Software Internationalisation and Localisation: An Introduction. New York: Van Nostrand Reinhold. 